\author{
Massimo Leone \\ Michael Bjørn Russell \\ Andrea Rigamonti \\ Angelo Attanasio \\ Licia Grazzi \\ Domenico D'Amico \\ Susanna Usai \\ Gennaro Bussone
}

\section{A study of Italian families with cluster headache}

M. Leone (西) • A. Rigamonti

A. Attanasio • L. Grazzi • D. D’Amico

S. Usai $\bullet$ G. Bussone

Carlo Besta National

Neurological Institute,

Via Celoria 11, I-20133 Milan, Italy

e-mail: leone@istituto-besta.it

Tel.: +39-02-2394264

Fax: +39-02-70638067

\section{Bjørn Russell}

Department of Neurology,

Copenhagen University Hospital,

University of Copenhagen,

Copenhagen, Denmark

\author{
Abstract A Danish genetic study \\ showed increased risk of cluster \\ headache $(\mathrm{CH})$ among relatives of \\ $\mathrm{CH}$ patients. We studied the families \\ of $191 \mathrm{CH}$ patients (118 males, 73 \\ females; mean age 45.9 years) \\ attending the Milan Headache \\ Center. Information on 3589 rela- \\ tives was collected by direct inter- \\ view of the probands $(\mathrm{n}=118)$ or \\ by mailed questionnaire $(\mathrm{n}=73)$. \\ The diagnostic criteria of the IHS \\ were used. A positive family history \\ was found in 19\% (37 of 191) of the \\ families. A total of 32 first-degree \\ (32 of 1036, 3.1\%) and 15 second-
}

degree (15 of $2553,0.6 \%$ ) relatives were affected. The relative risk of $\mathrm{CH}$ was 26.89 (95\% CI, 17.57$36.21)$ in first-degree relatives and 4.35 (95\% CI, 2.13-5.21) in seconddegree relatives. This study shows increased familial risk of cluster headache in an Italian population and confirms that cluster headache is, in some families, an inherited disorder.

Key words Cluster headache • Familial occurrence • Genetics

\section{Introduction}

Cluster headache is an uncommon, highly debilitating primary headache, characterized by brief, severe, unilateral headaches, accompanied by homolateral eye reddening, lacrimation, rhinorrhea, ptosis, etc. [1]. These attacks occur in cluster periods lasting weeks or months. The etiology and pathogenesis of this headache have not been clearly established. Until fairly recently, the disease was considered to be sporadic. However, a family history of cluster headache is reported in $2 \%-7 \%$ of patients [2-15]. Furthermore, the condition was described in both members of five pairs of monozygotic twins [16-18] and in three generations of a single family [19-21]. A Danish study [15] on cluster headache patients attending neurological clinics in Arhus, east-central Jutland, and Copenhaghen County, found that $7 \%$ (25 of 366) of patients had a family history of cluster headache, with 25 first-degree relatives and six second-degree relatives affected. The relative risk for the illness was 14- and 2-times greater, respectively, in first- and second-degree relatives of patients with cluster headache than in the general population. These findings constitute strong prima facie evidence that cluster headache has a heritable component in at least a fraction of patients. We designed a study to uncover evidence that genetic factors play a role in the genesis of cluster headache in an Italian population of cluster headache patients. To this aim, we assessed the relative risk of cluster headache in first- and second-degree relatives of cluster headache patients attending our headache center in Milan.

\section{Materials and methods}

We studied 191 patients (118 males, 73 females, average age 45.9 years) attending the Headache Center of the C. Besta National Neurological Institute, Milan. All patients (probands) were of 
Italian origin, alive, and diagnosed with cluster headache according to International Headache Society (IHS) criteria [1]. All underwent physical and neurological examination, cerebral computed tomography (CT) or magnetic resonance imaging (MRI) to exclude other general or neurological conditions. In 118 patients, information was obtained by direct interview during outpatient consultation or admission, and in 73 by means of a questionnaire sent by mail. In all cases, information on age at onset, duration of illness, frequency of attacks, duration of cluster period and attacks, character, location and intensity of the pain, and accompanying autonomic signs was collected. The number, sex and age of firstdegree and second-degree relatives, and whether or not they suffered from cluster headache were also ascertained. Living relatives reported as having cluster headache by the probands were interviewed by telephone to confirm or otherwise their condition. Relatives were interviewed when the proband reported phenomena reminiscent of possible cluster headache: unilateral head pain of brief duration ("a few hours"), pain attacks occurring in clustering or excruciating pain episodes, or pain episodes similar to those reported by the proband. Diagnosis of cluster headache in the relatives was done according to IHS criteria. For deceased relatives suspected of having suffered from cluster headache, the diagnosis was accepted only if the information provided by relatives was sufficiently detailed to apply the IHS diagnostic criteria for cluster headache.

\section{Statistical methods}

The probability that probands' relatives had cluster headache was estimated as a relative risk calculated by dividing the number of first- and second- degree relatives having the illness by the expected number as determined from the prevalence of cluster headache in the general population. Specifically the expression for relative risk is:

Prob (relative is affected I proband is affected)

Prob (random member of the population is affected)

A family aggregation is implied when the relative risk significantly exceeds 1 . The figure we used for the prevalence of cluster headache was based on that obtained in a study conducted on the population of San Marino [22]. In that study, the prevalence was 69 per 100000 for all ages combined. Since the prevalence of cluster headache varies with sex and age, and there were insufficient numbers affected in San Marino, to obtain reliable sex- and age-specific estimates of prevalence the overall prevalence of the San Marino survey was combined with the distribution of sex- and age at onset of probands of a previous Danish study [15]. This provided sexand age-specific prevalences of cluster headache (first-degree relatives only, because the ages of the second-degree relatives were often missing).

The relative risk of cluster headache was calculated for firstdegree and second-degree relatives. We determined $95 \%$ confidence intervals $(95 \% \mathrm{CI})$ for the frequency of cluster headache in first- and second-degree relatives and relative risk by assuming that the number affected followed a Poisson distribution. If there was more than one proband in a single family, the youngest was taken as the reference case and the family was counted only once.

\section{Results}

Of the 3589 relatives mentioned by the 191 probands, 1036 were of first degree (488 women and 548 men) and 2553 were of second degree (1234 women and 1319 men). A family history of cluster headache was reported by 37 (19\%) of the probands (13 women and 24 men). The total number of affected relatives was 47 (47 of 3589, 1.3\%). Of these, 11 were deceased but in all cases the information given by the probands was sufficient to diagnose cluster headache according to IHS criteria [1]. Thirty-two of the affected relatives were of first degree (32 of 1036, 3.1\%; 15 women and 17 men) and 15 were of second degree (15 of $2553,0.6 \%$; 5 men and 10 women) (Table 1$)$. The relative risks for cluster headache among the probands' family members were 26.89 (95\% CI, 17.57-36.21) for firstdegree relatives and 4.35 (95\% CI, 2.13-5.21) for seconddegree relatives (Table 2).

Table 1 Distribution by sex and presence of cluster headache in 1036 first-degree and 2553 second-degree relatives of 191 cluster headache patients

\begin{tabular}{lcrr}
\hline & Affected & Not affected & Total \\
\hline First-degree relatives & & & \\
$\quad$ Males & 17 & 533 & 550 \\
Females & 15 & 471 & 486 \\
Both genders & 32 & 1004 & 1036 \\
Second-degree relatives & & & 1319 \\
Males & 5 & 1314 & 1234 \\
Females & 10 & 1224 & 2553 \\
Both genders & 15 & 2538 & \\
\hline
\end{tabular}


Table 2 Relative risk of cluster headache in first-degree and second-degree relatives of 191 probands with cluster headache, standardized by age and sex

\begin{tabular}{llccccc}
\hline & \multicolumn{2}{c}{ Affected relatives, $n$} & & \multicolumn{2}{c}{ Population relative risk } \\
\cline { 2 - 3 } & Observed & Expected & & Observed/Expected & $95 \%$ CI \\
\hline First-degree relatives & 32 & 1.19 & & 26.89 & $17.57-36.21$ \\
Second-degree relatives & 15 & 3.45 & & 4.35 & $2.13-5.21$ \\
\hline
\end{tabular}

\section{Discussion}

This study has revealed that the relatives of an Italian population of cluster headache patients have a much greater risk of developing the disease than the general population. The risk is particularly high for first-degree relatives, but is less so for second-degree relatives. These findings are in agreement with those of a previous study on a Danish population of cluster headache patients [15], and provide further evidence that in some patients a genetic component influences the development of cluster headache. In theory, one cannot exclude that the increased familial risk is due to some shared environmental factor. However, the very high relative risk among first-degree relatives indicates that this an extremely unlikely possibility [23]. Among the possible limitations of the present study, we note that the probands were not selected from the general population but from a specialized headache center. There is also the fact that the general population data we used were extrapolated from a study conducted before the introduction of the International Headache Society diagnostic criteria [22].

It is also important to note that $30(25 \%)$ of the 118 probands of the study interviewed directly referred to family members with cluster headache, while only 7 (9.5\%) of the 73 probands sent postal questionnaires did so. This indicates that the method of postal interview may result in underestimation of the extent of family involvement among cluster headache patients. To conclude, our study provides further indication that cluster headache has a hereditary component in some families. Future studies will aim to identify the gene or genes involved.

\section{References}

1. Headache Classification Committee of the International Headache Society (1988) Classification and diagnostic criteria for headache disorders, cranial neuralgias and facial pain. Cephalalgia 8[Suppl 7]:1-96

2. Kunkle EC, Pfeiffer JB Jr, Wilhoit WM, Hamrick LW Jr (1952) Recurrent brief headache in "cluster pattern". Trans Am Neurol Assoc 77:240-243

3. Bickerstaff ER (1959) The periodic migrainous neuralgia of Wilfred Harris. Lancet 1:1069-1071

4. Schiller F (1960) Prophylactic and other treatment for "histaminic" cluster, or "limited variants of migraine." J Am Med Assoc 173:1907-1911

5. Duvoiosin RC, Parker GV, Kenoyer WL (1961) The cluster headache. Arch Intern Med 108:111-116

6. Nieman EA, Hurwitz LJ (1961) Ocular sympathetic palsy in periodic migrainous neuralgia. J Neurol Neurosurg Psychiatry 24:369-373

7. Balla JI, Walton JN (1964) Periodic migrainous neuralgia. $\mathrm{Br}$ Med $\mathrm{J}$ 1:219-221

8. Eadie MJ, Sutherland JM (1966) Migrainous neuralgia. Med J Australia 53:1053-1056
9. Lance JW, Anthony M (1971) Migrainous neuralgia or cluster headache? J Neurol Sci 13:401-414

10. Ekbom K (1974) Clinical aspects of cluster headache. Headache 13:176-180

11. Kudrow L (1980) Cluster headache, mechanism and management, 1 st edn. Oxford University, Oxford

12. Manzoni GC, Terzano MG, Bono G, Micieli G, Martucci N, Nappi G (1983) Cluster headache clinical findings in 180 patients. Cephalalgia 3:21-30

13. Andersson PG (1995) Migraine in patients with cluster headache. Cephalalgia 5:11-16

14. Montagna P, Mochi M, Prologo G, Sangiorgi S, Pierangeli G, Cevoli S et al (1998) Heritability of cluster headache. Eur J Neurol 5:343-345

15. Russell MB, Andersson PG, Thomsen LL (1995) Familial occurrence of cluster headache. J Neurol Neurosurg Psychiatry 58:341-343

16. Couturier EG, Hering R, Steiner TJ (1991) The first report of cluster headache in clinical twins. Neurology 41:761
17. Rogeberge C, Bouchard JP, Simard D, Gagne R (1992). Cluster headache in twins. Neurology 42:1255-1256 (letter)

18. Sjaastad O, Shen JM, Stovner LJ, Elsas $\mathrm{T}$ (1993) Cluster headache in identical twins. Headache 33:214-217

19. Spierings EL, Vincent AJ (1992) Familial cluster headache, occurrence in three generations. Neurology 42:1399-1400

20. Alberca R, Aguilera JM, Casado JL, Lopez JM, Arenas C, Moreno A et al (1994) Headache en racimos de presentacion familiar. Neurologia 9:22-24

21. D'Amico D, Leone M, Moschiano F, Bussone G (1996) Familial cluster headache: report of three families. Headache 36:41-43

22. D'Alessandro R, Gamberini G, Benassi G, Morganti G, Cortelli P, Lugaresi E (1986) Cluster headache in the Republic of San Marino. Cephalalgia 6:159-162

23. Khoury MJ, Beaty TH, Liang K-Y (1988) Can familial aggregation of diseases be explained by familial aggregation of environmental risk factors? Am J Epidemiol 127:674-683 